\title{
UN ANÁLISIS DIPLOMÁTICO A LA CORRESPON- DENCIA DE LOS VIRREYES DEL PERÚ (1698-1821) ${ }^{1}$
}

\author{
Giovanna VALENCIA ÁlVAREZ \\ Pontificia Universidad Católica del Perú
}

\begin{abstract}
RESUMEN: Los preceptos legales recogidos en diferentes códigos del derecho indiano como: la Recopilación de Leyes de Indias, el Cedulario Indiano o la Novísima Recopilación reglamentaron las funciones de las autoridades, como es el caso de las disposiciones dadas al Virrey y al Secretario o Escribano de Gobernación, el modo de custodiar los papeles del despacho y los formulismos que debían tenerse en cuenta al momento de redactar la documentación colonial. El presente ensayo tiene como objetivo efectuar un análisis diplomático de la correspondencia que intercambiaron los funcionarios y los particulares con los Virreyes del Perú
\end{abstract}

PALABRAS CLAVE: Virreyes del Perú/ Secretario de Gobernación/ Escribano/ Archivo/Diplomática/ Correspondencia.

ABSTRACT: The legal precepts gathered in diferents codes of the Indian laws like: the compilation of the Laws of Indian, Indian Cedulario or Collecting the Novisima regulate the functions of the authorities, such as the case of the rules given to the Viceroy and the Secretary of administration, the way of guardiang the office's papers and the formalities that was supposed to be taken in consideration at the moment of writing the colonial documentation. This essay has as an objective to make a diplomatic analysis of the corresponded that was interchanged by the public officials and the particular members with the Viceroy of Peru.

KEYWORDS: Viceroy of Peru; Secretary of administration; notary; registry; diplomatic analysis, the corresponded.

Con motivo de la promulgación de la Real Cédula del 20 de noviembre de 1542 el Rey Carlos I de España dispuso la creación del Virreinato del Perú, en reemplazo de las gobernaciones de Nueva Castilla y Nueva León fundadas por los conquistadores. A partir de ese momento se instauró un nuevo régimen político, administrativo, económico, social, religioso y cultural que continuó por casi tres siglos.

Al formarse esta nueva sociedad y establecerse, con ella, sus representantes con

${ }^{1}$ Recibido el 7 de septiembre de 2011. Aceptado en el consejo de 8 de noviembre de 2011. 
las competencias propias de su envergadura, se incorporaron una serie de disposiciones jurídicas procedentes de las Coronas de Castilla y de Aragón, que organizaron y ordenaron el estatus quo del Virreinato Peruano.

Los preceptos legales recogidos en diferentes códigos del derecho indiano como: la Recopilación de Leyes de Indias, el Cedulario Indiano o la Novísima Recopilación reglamentaron las funciones de las autoridades, como es el caso de las disposiciones dadas al Virrey y al Secretario o Escribano de Gobernación, el modo de custodiar los papeles del despacho y los formulismos que debían tenerse en cuenta al momento de redactar la documentación colonial.

El presente ensayo tiene como objetivo efectuar un análisis diplomático de la correspondencia que intercambiaron los funcionarios y los particulares con los Virreyes del Perú, debido a que esta revela un alcance de como se reguló casi continua y hasta insistentemente el estilo de las comunicaciones.

\section{EL VIRREY, SU SECRETARIO Y EL ARCHIVO}

Uno de los legados de la Corona de Aragón para las Indias fue la investidura del Virrey, quien fue un funcionario nombrado por el Rey de España ${ }^{2}$ a propuesta del Consejo de Indias para gobernar territorios conquistados. Desde el momento de su designación asume la representación personal de la autoridad real en el virreinato convirtiéndose en su "Álter Ego", es decir, "su otro yo"; sin embargo, si el Monarca Español ejerció una autoridad absoluta, no pasaba lo mismo con su representante en Indias quien al ser un funcionario de capa y espada compartió el poder con la Audiencia en casos de justicia, la que funcionó como un contrapeso en la conducción del gobierno ${ }^{4}$.

El Virrey del Perú residió en la ciudad de Lima, conocida como la Ciudad de Los Reyes, el primer virrey fue Blasco Núñez de Vela y el último fue José de la Serna; gobernaron el Perú cuarenta virreyes en tanto se prolongó la presencia de la

2 "Recopilación de Leyes de Indias". [Recurso electrónico] <http:www.congreso.gob.pe/ntley/ LeyIndiaP.htm.>. Libro Tercero, Título I, Ley 1 "mandamos que los Reinos del Perú y Nueva España sea regidos y gobernados por Virreyes, que presente nuestra real persona y tenga el gobierno superior." [Consultado: 03.04.2011]

${ }^{3}$ Ibídem. Ley 2 "mandamos (...) que los obedezcan y respeten como a persona que representan la nuestra, guarden, cumplan y ejecuten sus órdenes y mandatos por escrito o de palabra, y a sus cartas, órdenes y mandatos no pongan escusa, ni dilación alguna"

4 Ibídem. Ley 37 "cuando se trataren en los acuerdos de las audiencias materias civiles o criminales (...) los Virreyes del Perú y Nueva España dejen responder y proveer al oidor más antiguo (...) asi por no tener voto como porque los jueces tengan libertad para proveer justicia" 
Monarquía Española en América. El virrey permanecía en el cargo hasta un tiempo máximo de tres años ${ }^{5}$, límite que podía variar dependiendo de la voluntad del soberano, tal es el caso del virrey José Antonio Manso de Velasco, Conde de Superunda, quien gobernó el Perú desde 1745 a 1761 prolongando su mandato por 16 años ${ }^{6}$.

El Virrey durante el desempeño de su cargo cumplió diferentes funciones:

$\checkmark$ A nivel político: fue el jefe del gobierno colonial con todos los derechos y obligaciones.

$\checkmark$ A nivel legislativo: dictó leyes y ordenanzas en las colonias, dando cuenta de ello al Consejo de Indias.

$\checkmark$ A nivel judicial: ejerció la presidencia de la Audiencia, pero "sin derecho a voto" $"$.

$\checkmark$ A nivel militar: fue el jefe supremo militar desempeñándose como Capitán General en el Virreinato.

$\checkmark$ A nivel económico: fue el encargado de la fiscalización y del control de los ingresos que recibía la Real Hacienda, a través de los impuestos y tributos.

$\checkmark$ A nivel religioso: desempeñó el cargo de Vicepatrono de la Iglesia Católica, lo cual lo facultaba a nombrar autoridades eclesiásticas de menor jerarquía. ${ }^{8}$

Las actividades administrativas tramitadas en el despacho virreinal estaban a cargo de un grupo de empleados subordinados al virrey, uno de los más importantes nombrado por el monarca español fue el oficio de Escribano de Gobernación ${ }^{9}$ o Secretario, cargo perpetuo e irrenunciable, el cual además de

${ }^{5}$ Ibídem. Ley 71 "que los virreyes sirvan en sus cargos por tiempo de 3 años contados desde el día de posesión"

${ }^{6}$ G. VALENCIA ÁLVAREZ. (2002). «Superior Gobierno: su reorganización y descripción dentro del proyecto de Informatización del Archivo General de la Nación». Revista de Archivo General de la Nación (AGN). 24 p. 47.

7 T. HAMPE MARTíNEZ. (1990-1992). «Esbozo de una transferencia política: asistentes de Sevilla en el gobierno virreinal de México y Perú». Revista Histórica, XXXVII p. 137

${ }^{8}$ Para mayor detalle de las funciones del virrey consultar mi artículo citado en la Revista del AGN $\mathrm{N}^{\circ} 24$ pp. $45-60$.

${ }^{9}$ Recopilación... ob.cit. Libro Quinto, Titulo VIII, Ley 1 "que los virreyes no puedan nombrar escribanos y hayan de sacar título del Rey despachado por el Consejo de Indias"

En el artículo de P. HidAlgo Nuchera (1994). «El Escribano Público entre Partes o Notarial en la Recopilación de Leyes de Indias de 1680». [recurso electrónico]. Espacio, Tiempo y Forma, 1994, 
cumplir una serie de funciones ${ }^{10}$ como la expedición de copias de títulos, cédulas y otros, la preparación y redacción de instrucciones, el manejo del $\operatorname{archivo~}^{11}$ y la confección de los libros de registro ${ }^{12}$, participó con el virrey en sesiones en las cuales se debía de garantizar la confidencialidad de la información ${ }^{13}$. Un destacado representante de ese puesto fue Sancho de Salinas, conocido al tomar los hábitos como Fray Buenaventura de Salinas y Córdova, fue un criollo peruano que se desempeñó el cargo de Secretario de Gobernación; uno de sus mayores logros fue la organización del archivo del palacio virreinal por orden del Marqués de Montesclaros, convirtiéndolo en "un diestro manipulador de documentos y un avisado funcionario que conocía las intimidades de la política y los mayores secretos de la administración." 14

De la mano con el Secretario surgieron dos instrumentos fundamentales para complementar satisfactoriamente sus labores y que contribuyeron en una mejor gestión en la administración virreinal: primero, la normatividad dictada desde la época de los Reyes Católicos quienes mandaron a los escribanos a conservar los documentos en sus oficinas, lo que trajo como consecuencia la fundación del archivo y su regulación mediante la promulgación, en 1633 de las nuevas ordenanzas para el Archivo de Simancas y que continuo, en el siglo XVIII, con la

serie IV, t. 7. 〈http://www.e-spacio.uned.es/fez/eserv.php?pid=bibliuned: ETFSerie4... 3C09 ...> [Consultado: 18.07.2011]. Se subraya que el escribano cumplía las funciones que actualmente desempeña un secretario como ser "encargado de escribir la correspondencia, extender las actas, dar fe de los acuerdos y custodiar los documentos de una oficina. En Indias realizaba sus cometidos en las audiencias, gobernaciones, cabildos, etc. Organismos todos ellos que carecían precisamente de la figura del secretario lo que nos revela la auténtica función del escribano."

${ }^{10}$ G. Lohmann Villena. (2005). «El Secretario Mayor de Gobernación del Virreinato del Perú: notas para su estudio histórico institucional». [recurso electrónico]. Revista de Indias, 2005, vol. 65. $\mathrm{n}^{\circ} 234<$ <ttp://www.revistadeindias.revistas.csic.es/index.php/.../article/.../393 .> [Con-sultado: 20.04.2011].

${ }^{11}$ D. DE EnCINAS. (1945). Cedulario Indiano. Madrid: Cultura Hispánica. Libro I. Ordenanza de 1575 en la cual se "manda que cuando los escribanos de cámara y gobernación entraren a servir sus oficios se les entreguen los papeles por inventario"

12 Recopilación... ob. cit. Libro Quinto, Título VIII, Ley 16 "que los escribanos guarden y tengan en su poder registro de todas las escrituras, autos e informaciones." Se puede revisar en el AGN. Superior Gobierno. GO-BI 1. Legajo 47, documento 658 el Libro de Registro de la Secretaría de Cámara del Virrey del Perú correspondiente al período 1797 a 1804.

13 Ibídem. Libro. Tercero, Título III, Ley 47 “que en casos de secreto puedan los virreyes despachar con sus secretarios los negocios que por cualquier vía les pareciere se debe guardar secreto"

${ }^{14}$ B. DE SAlinas y CóRdova. (1957). Memorial de las Historias del Nuevo Mundo del Pirú. Lima: Universidad Nacional Mayor de San Marcos. p. 23 
creación del Archivo de Indias de Sevilla. Fue tan importante el rol del archivo ${ }^{15}$ que en las memorias entregadas por los virreyes al finalizar su mandato dejaban instrucciones para el buen funcionamiento de su gobierno, este es el caso del Marqués de Montesclaros quien "recomendaba a su sucesor resolver los papeles de la administración y confesaba que nunca encontró amigo más fiel ni consejo más seguro que en el archivo" ". En segundo lugar la aparición del archivero como figura elemental en la organización de los papeles de la secretaría del virrey y que, si bien es cierto estas funciones en un inicio las desempeñaba el Secretario, para el siglo XVII sus actividades serán reglamentadas a tal punto que no sólo se dedicara a guardar y custodiar los expedientes, como se dispuso en la Recopilación de Indias en la que se mandaba que una de las llaves del Archivo del Consejo debía ir a manos del Archivero ${ }^{17}$ sino que también desarrollará una labor permanente de ordenación convirtiéndose en "memoria viva de la secretaria"18.

Con estas dos herramientas el virrey y sus funcionarios pudieron mantener una estrecha comunicación con el Rey a través de su Consejo de Indias remitiendo un gran volumen de documentación que detallaba lo que acontecía en el territorio que tenía bajo su jurisdicción, debido a esta información recogida en los diferentes tipos documentales que se emitían en su despacho, en especial en la correspondencia, se ha podido rehacer parte de la estructura y la organización indiana.

\section{LA CORRESPONDENCIA: INSTRUMENTO DE GOBIERNO}

Cuando hablamos de la correspondencia para la etapa colonial debemos indicar que esta no habría sido tan abundante, en las diferentes instituciones virreinales, si es que antes no se hubiesen puesto en práctica las disposiciones legales que la Corona había implementando en lo relativo al registro y al archivo de sus papeles, no obstante, se debe recalcar que la escritura como medio de trasmisión y la reducción del analfabetismo, ampliándose el número de miembros de la burocracia

${ }^{15}$ Recopilación... ob. cit. Libro Segundo, Título II, Ley 67. "la experiencia ha mostrado que por no haber archivo en el Consejo de Indias se han perdido muchos papeles importantes de diferentes materias para el buen gobierno de aquellas (...) mandamos que en el dicho Consejo haya un archivo cerrado y guardado donde estén los papeles "

16 J. M. LuZ UrQuiJo (1998). El Agente de la Administración Pública en Indias. Buenos Aires: Instituto de Investigaciones de Historia del Derecho. p. 313

${ }^{17}$ Recopilación... ob. cit. Libro Segundo, Título II, Ley 67.

18 J. PRADELls NADAl y OtRo. (1986-1987). «Los archiveros de la primera secretaria de estado (siglo XVIII)». [recurso electrónico], 1986-1987, $\mathrm{n}^{\circ}$ 6-7. <http://www.rua.ua.es/dspace/ bitstream/10045/5008/1/RHM_06-07_06.pdf>. [consultado:04.03.2011] 
indiana que aprendió no sólo a leer sino a escribir a partir del siglo $\mathrm{XVI}^{19}$, fueron factores primordiales para el incremento de la masa documental; además de que los españoles tuvieron una fuerte inclinación por plasmar todo acto probatorio o informativo en el papel y por escrito ${ }^{20}$. Gracias a estos elementos es que la correspondencia se convirtió en el vehículo de comunicación "más normal y de menor rigor en cuanto a su aspecto formal y que trasmitía todo tipo de información ya sea particular $u$ oficial ${ }^{, 21}$, debido a ello se considero un valioso instrumento de gobierno porque daba a conocer diferentes aspectos de la administración colonial.

Para redactarlas fue necesario establecer una serie de formulismos de los más sencillos en comparación a la documentación generada producto de otras funciones incluyendo al expediente ${ }^{22}$. Las disposiciones abarcaron desde aquellas en las que se instaba a los funcionarios a dejar en libertad a las personas que quisieran comunicarse con el $\operatorname{Rey}^{23}$ y con su representante en Indias, el virrey ${ }^{24}$ por ello gran

${ }^{19}$ P. L. LORENZO CADARSO. (2002). «La correspondencia administrativa en el Estado Absoluto Castellano (siglo XVI-XVII)». [recurso electrónico]. Tiempos modernos: Revista Electrónica de Historia Moderna, 2002, vol. 3, $\mathrm{n}^{\circ}$ 5, <http://www.tiemposmodernos.org/include/getdoc. php?id= 124article... > [consultado:10.11.2010].

${ }^{20}$ A. GuEvara GiL. (1996). «Una hipótesis de trabajo sobre la función de la carta de venta en el derecho colonial peruano ¿formalidad esencial o legalismo obsesivo?». [recurso electrónico]. Revista de Estudios Históricos-Jurídicos, 1996, vol. XVIII. <http://www.restudioshistoricos. equipu.cl/index. $\mathrm{php/rehj/article/viewFile/.../232.>} \mathrm{[consultado:04.02.2011].} \mathrm{"La} \mathrm{recurren-cia} \mathrm{constante} \mathrm{al} \mathrm{medio}$ escriturario tenia por objeto contar con pruebas destinadas a promover el respeto de los derechos y en ultima instancia a proveer los fundamentos probatorios para reclamar algún tipo de indemnización posterior si acaso la corona decidía avasallar los derechos de sus vasallos (..) la necesidad de verificar por escrito los negocios públicos y privados se hizo presente (...) la palabra escrita sobrepaso en la veracidad y autenticidad a la palabra oral (...) en el derecho español un instrumento escrito también poseyó mas valor probatorio que de testimonios orales.

${ }^{21}$ G. VALENCIA. Ob. cit. p. 50

22 J. M. Luz UrquiJo. Ob. Cit. p. 296: En México el virrey Conde de Revilla Gigedo describió como debía ser el cuerpo del expediente "cosido y fojeado traerá en su fachada las expresiones del día, mes y año en que se comienza (...) y un breve extracto de la materia."

${ }^{23}$ D. DE ENCINAS. Ob. Cit. Libro II Provisión 14.08.1509 "manda que dejen libremente a todas las personas que estuvieren en las Indias escribir a su Majestad y su consejo y otras personas lo que quisieren".

Libro II. Cédula del 17.10.1575. "que tengáis mucho cuidado que todas y cualesquier cartas y despachos que se nos escribieren y quisieren enviar por cualquier ciudades (...) y personas particulares (...) se nos traigan y envien a muy buen recaudo (...) y no consintáis, deis lugar a que en manera alguna se tomen no detengan".

Recopilación...ob.cit. Libro Tercero, Título XVI, Ley 6 "que la correspondencia con las Indias sea libre y sin impedimento (...) para que les entreguen y envíen a buen recaudo y no los abran, lean, ni retengan en su poder" 
volumen documental pertenece a las comunicaciones que las autoridades y particulares mantuvieron con él para exponerle, solicitarle o tan sólo transmitirle cualquier hecho o acontecimiento ${ }^{25}$ hasta aquellas en las que se establecía la forma en que debían de redactarse los documentos.

Al haber sido la carta uno de los instrumentos más recurrentes y utilizados se debe precisar que el concepto de carta, en la época colonial, también fue empleado para referirse a otros tipos documentales como las escrituras públicas, otorgadas ante el escribano por personas naturales, a las cuales se les denominaba cartas de poder, de obligación, de censo entre otras dependiendo del negocio jurídico ${ }^{26}$ que se trataba en ellas. De la misma forma se llamaba carta a aquellos tipos documentales en los cuales el Rey y su Consejo anunciaba a sus representantes en Indias el otorgamiento de una merced de tierras, el nombramiento en algún cargo o algún otro asunto de carácter público. Ambas agrupaciones, pertenecientes tanto a la jurisprudencia privada como pública, generaron al ponerse por escrito obligaciones y derechos al ser considerados, debido a su actuación y su escrituración ${ }^{27}$, como documentos probatorios o dispositivos. A diferencia de lo que conocemos como carta o correspondencia, que en un concepto fácil y claro podría definirse como aquel instrumento que trasmite información pero que no genera derechos ni obligaciones por ser un documento lato sensu ${ }^{28}$, expresión latina usada en derecho para definir a aquel documento que carece de las cualidades que

${ }^{24}$ Ibídem Ley 3 "que quien hubiere de dar cuenta al Rey de alguna cosa que convenga proveer, acuda primero a los virreyes".

${ }^{25}$ M. MoReyra y PAZ SoldÁn. (1952). «Introducción a documentos y cartas de la Audiencia y del virrey Marques de Montesclaros». Revista Historia, XIX. pp. 217-218. "Entre las fuentes más importantes, trasmitidas por escrito y que utiliza la historia para descubrir el pasado: están las cartas (...) en su gran mayoría, exhiben confidencias personales teñidas de subjetivismo, mas no corto sector, como en el presente caso, traen contenido documental e informativo.

${ }^{26}$ J. M. LÓPEZ VilLALBA. (1997). «Las relaciones del concejo bajo medieval. Estudio diplomático de las cartas concejiles de Guadalajara (1391-1496)». [recurso electrónico]. Espacio, Tiempo y Forma, 1997, serie III, $\mathrm{n}^{\mathrm{o}}$ 10, <http://www.e-spacio.uned.es/fez/eserv.php?pid= bibliuned: ETF0A818B05-68AE....> [consultado: 12.03.2011].

27 J. Bono. (1996). «Diplomática Notarial e Historia del Derecho Notarial». [recurso electrónico]. Cuadernos de Historia del Derecho, 1996, nº3. <http://www.revistas.ucm.es/der/ 11337613/ articulos/CUHD9696110177A.PDF .> [consultado: 23.01.2011].

${ }^{28}$ H. Moreno Burgos. (2004). «Fórmulas de cortesía en las cartas de Pedro de Valdivia». [recurso electrónico]. Protocolo. Org. Beta 2.1. <http://www.protocolo.org/.../fórmulas_de_ cortesía_en_las_cartas_>_[consultado: 18.02.2011] "Los documentos lato sensu tienen por fin asegurar o dar a conocer la realización de las órdenes del soberano, se caracterizan por la libertad de redacción en forma expositiva, pocas fórmulas y solemnidades " 
lo harían rigurosamente jurídico y diplomático. Es este último concepto el que nos interesa analizar a continuación.

\section{ANÁLISIS DIPLOMÁTICO DE LA ESTRUCTURA DE UNA CARTA}

La diplomática es una ciencia que nos brinda las herramientas necesarias para enjuiciar la autenticidad de un documento, datarlo en caso de no identificarse la fecha o el lugar de emisión, reconocer la forma en que ha llegado a nosotros, sea original, copia o borrador, y efectuar un estudio de sus caracteres internos y externos.

Para proceder con el análisis diplomático de la estructura de la carta como tipo documental se ha tenido en cuenta el contexto político, social y cultural en el cual se emitían, debido a que los formulismos iban cambiando según el tiempo y el espacio. De acuerdo a esto, lo que nos interesa en este análisis, además de la forma externa será también su disposición material y la ordenación interna del discurso.

La evolución de la estructura de una carta responde a una reglamentación de su redacción a través de diferentes etapas en las cuales la Monarquía Española intento corregir los excesos y agilizar la rapidez en las respuestas, debido a que la tramitación de por si era bastante lenta sin contar el tiempo que se demoraba para llegar a España.

Durante el reinado de Felipe II, en 1586 se publicaron una serie de dispositivos contenidos en la Pragmática de los Tratamientos y Cortesías ${ }^{29}$, con la finalidad de simplificar el uso de los formulismos, la forma del cuerpo del texto y la manera en que debían de enviarse las cartas a Indias. Hasta antes de la Pragmática, se empleaba un margen reducido, se escribía de manera horizontal, se cumplía con el uso de una serie de fórmulas de sometimiento ${ }^{30}$ y de la mención en extenso de los cargos y títulos honoríficos.

La Pragmática llega a América al año siguiente de su promulgación con el objetivo de dar cumplimiento a una serie de instrucciones como la eliminación de la fórmula del sometimiento, considerando sólo la fórmula de la despedida antes de la firma y suscripción del otorgante, se amplía el margen del texto cerca de un tercio del folio y en el reverso del mismo se indicaba la dirección del remitente.

29 A. Heredia Herrera. (1985). Recopilación de Estudios de Diplomática Indiana. Sevilla: Excma. Diputación Provincial de Sevilla. p. 7.

${ }^{30}$ Ibídem. p. 131 
En 1595 mediante una Real Cédula se difunde un mandamiento por el cual los virreyes debían de normalizar el envío de su correspondencia por ser de importancia y de tan variado contenido ${ }^{31}$. Adicionalmente a ello, se debía dejar el cincuenta por ciento del margen del texto ${ }^{32}$ y escribir en vertical con el objetivo de destinar ese espacio para los resúmenes ${ }^{33}$; igualmente existió una preocupación constante en la manera en que debía de escribirse por ello se regulo esta materia para que la escritura fuera clara y sencilla ${ }^{34}$.

A pesar de todo las normas que se fueron dando en diferentes momentos, como la Real Cédula del 25 de diciembre de 1748 en la cual se ordenaba que los documentos se despacharan con un índice, el mismo que debía contener de manera breve el asunto y la fecha de los documentos ${ }^{35}$ y ya cerca de finalizado el siglo XVIII, con una Real Orden se reiteraba nuevas indicaciones al Virrey del Perú sobre el destino de la correspondencia y otros añadidos ${ }^{36}$, estas parecen no haberse

${ }^{31}$ Cedulario Indiano Libro I ob. Cit. Real Cédula del 15.10 .1595 en la que se manda al virrey del Perú, Luis de Velasco "que por no venir las cartas que se me escriben y los recaudos, informaciones e papeles que con ellas vienen en la forma que convenía se ocupa mucho tiempo en verlos e por el consiguiente en responder por la confusión que causan y es justo ganar todo el tiempo que se pudiere para el Consejo (...) es mi voluntad (...) para que mejor e con mas claridad puedan acertar, mando que (...) las cartas que me enviare des vengan escritos en papel doblado a la larga, por manera que de otra tanta margen como fuere lo escrito y en aquella margen frontero de cada capitulo al principio del sacada en relación la sustancia del mismo capitulo, y en lo que toca a los papeles que hubieren de venir con ella poner en la cubierta de cada recaudo de por si la fecha de la carta y numero del capitulo donde se cita y todo lo que se acostumbra a escribir en muchas cartas lo reduzcáis a cuatro por sus materias distintas gobierno, justicia, guerra y hacienda."

${ }^{32}$ Recopilación...ob.cit. Libro Segundo, Título XV, Ley 6 "para mayor claridad y expedición de los negocios y correspondencias, que los virreyes han de tener con nos ordenaran a sus secretarios, que numeren y dividan las cartas por materias y escriban a media margen sacada en la otra relación sucinta de lo que contiene".

${ }^{33}$ A. Heredia HerRera. Ob.cit. p. 134

34 Recopilación...ob.cit. Libro Tercero, Título XVI, Ley 1 “mandamos (...) que en la forma de escribir y darnos cuenta (...) que el estilo sea breve, claro y substancial y decente, sin generalidades y usando palabras que con más propiedad puedan dar a entender la intención de quien escribe".

35 A. HEREDIA HERRERA. Ob. cit. p. 146. Se puede consultar en el AGN. Superior Gobierno GOCO 2 203.1067. Índice de envío de cartas de 1771.

${ }^{36}$ Reales Cédulas, Reales Ordenes, Decretos, Autos y Bandos que se guardan en el Archivo Histórico. Ministerio de Hacienda y Comercio. (1947). Lima: Archivo Histórico Sección Colonial, p 217. "Copia real orden al Virrey del Perú. Comunicando que para evitar confusiones al abrirse la correspondencia tanto de España como de sus dominios en lo referente a los diversos Ministerios, $\mathrm{Su}$ Majestad ha resuelto que en los sobrescritos de las cartas pertenecientes al departamento de Marina se añada, después de poner el nombre del Secretario real: secretario de estado y del despacho universal de Marina. Madrid, 15.06.1787”. 
cumplido en su totalidad y por ello la reglamentación sobre el cumplimiento de las formas fue constantemente recordada a los funcionarios en Indias.

El Corpus Documental que va a ser producto del análisis diplomático pertenece a la serie Comunicaciones del Fondo Superior Gobierno que se conserva en la Sección Colonial del Archivo General de la Nación - AGN.

El primer grupo pertenece a la sub serie Borradores del Virrey y que abarca desde 1702 con el gobierno Melchor de Portocarrero y Laso de la Vega hasta 1821 con el virrey Joaquín de la Pezuela.

El término borradores implica hablar de la tradición documental debido a que existió toda una normativa sobre la custodia de los originales y las $\operatorname{copias}^{37}$, no obstante la calificación de borrador supone características específicas como el presentar enmiendas y carecer de la subscripción y la firma del autor de la carta al no ser aún su última disposición.

Al realizar el estudio diplomático de este grupo se debe precisar que los borradores, estarán privados de ciertos elementos internos que le otorguen la validez y la autenticidad que se requiere en un documento diplomático, a pesar de ello se puede hallar algunos detalles para su análisis.

La apariencia externa del borrador de una carta o correspondencia es la siguiente:

a) Materia escriptoria: el papel elaborado de trapos (cáñamo y celulosa de algodón) mediante un sistema de molturación

b) Formato: un cuadernillo de dos folios a más.

c) Instrumento escriptorio: la pluma y la tinta ferrogálica de color negro que con el paso del tiempo cambia a color marrón.

d) Tipo de escritura: en América se empleo la letra Bastardilla o Itálica, la que en España se denomino Humanística Cursiva.

La disposición interna esta compuesta de una estructura que es la que sigue:

1. Protocolo Inicial

37 J. M. Morales Folguera. (2001). La Construcción de la Utopía. El Proyecto de Felipe II (1556-1598) para Hispanoamérica. Madrid: Biblioteca Nueva, p. 36-37. "Los originales habían de quedar en los lugares que habian sido hechos y las copias habian de enviarse a las autoridades respectivas para que las mandasen a su vez al Consejo de Indias". 
a) Invocación: el crismón o cruz en la parte superior medio del folio.

2. Cuerpo

b) Texto: exposición narrativa de los hechos o acontecimientos.

c) Fórmula de despedida

\section{Protocolo Inicial o Escatocolo}

4. Data tópica y crónica: el lugar y la fecha de emisión puede ir precedida de las preposiciones DE o EN.

5. Dirección: destinatario de la carta ubicado en la parte inferior izquierda

6. Al dorso: la dirección, la data tópica y crónica y un resumen del contenido de la carta.

La segunda parte del análisis corresponde a la sub serie llamada Oficios al Virrey que va desde $1698^{38}$ a 1821 . Este grupo esta conformado por originales debido a las características y los formulismos que se aprecia en los documentos.

El análisis de los caracteres externos es el mismo que el empleado para los borradores, no obstante en este conjunto se presenta una distinción en la escritura ${ }^{39}$ debido a que el autor de la carta y el que la redacta solían ser dos personas diferentes, a este tipo de carta se le denomina heterógrafas.

En el caso del esquema interno, se debe tener en cuenta que esta es muy similar a la de la petición ${ }^{40}$ del siglo XVI la misma que se podrá adaptar a la correspondencia del siglo XVII al XIX, salvo mínimas modificaciones y es la siguiente:

\section{Protocolo Inicial}

${ }^{38}$ Las fechas extremas correspondiente a esta sub serie han sido extraídas de la Guía del Archivo General de la Nación (2009), sin embargo se ha encontrado documentación que data de años anteriores.

39 M.C. GIL ARRAN. (1986). «Contribución al Estudio Lingüístico del Siglo XVII». [recurso electrónico]. Cauce Revista de Filología y su Didáctica, 1986, 9 http://www.cvc.cervantes.es/ literatura/cauce/pdf/cauce09/cauce_09_004.pdf [Consultado: 31.05.2011]. La autora se refiere a esta distinción en el tipo de letra como "variedad caligráfica".

${ }^{40}$ O. Huamanchumo DE LA CubA. (en preparación) «Tradiciones Discursivas en Documentos Petitorios Indianos (Perú Siglo XVI)» Actas del VIII Congreso Internacional de Historia de la Lengua Española, Santiago de Compostela, 14-18 de Septiembre de 2009, 1-15 (manuscrito). 
a) Cruz

b) Dirección en vocativo: tratamiento de la persona a la que va dirigida la carta, en este caso al Excelentísimo Señor.

2. Cuerpo

c) Texto: expositivo y narrativo

d) Fórmula del despedida

3. Protocolo Final o Escatocolo

e) Datación tópica y crónica: compuesta por el lugar, más la indicación del día, mes y año (DD/MM/AA) o mes, día y año (MM/DD/AA).

f) Fórmula de sometimiento o cortesía

g) Fórmula nominal de despedida: Ex. Sr. (Excelentísimo Señor).

h) Validación: suscripción completa del autor (nombre, apellido y rúbrica).

Hacia fines del siglo XVI y durante los siglos XVII y XVIII se debieron de haber puesto en práctica, en América, todas las disposiciones que se habían promulgado en torno a la forma de redacción y formato externo de los documentos, en especial en lo que se refiere a la correspondencia, a pesar de ello como vamos a demostrar en el análisis de las siguientes láminas en muchos casos las normas no fueron aplicadas lo que aún así no invalida la autenticidad del documento diplomático.

\section{APÉNDICE}

\section{Lámina $\mathbf{I}^{41}$}

Protocolo Inicial: Invocación: Crismón

\section{Cuerpo:}

He recebido su carta de vuestra merced/ de 28 de maio con el duplicado/ de la que escribió al Governador y/ Oficiales Reales de Buenos Ayres dandoles/ la instruccion y forma que han de/tener para la aberiguacion de plata/ sin quintar y su aprehension en que/ ha cumplido vuestra merced con lo que le ordene/ mostrando el celo del maior ser/vicio de su Magestad con el acierto/ que esperaba de su prudencia y expe/riencias.

Fórmula de despedida: Nuestro señor guarde a vuestra merced muchos años.

${ }^{41}$ AGN. Superior Gobierno. Borradores de Oficios del Virrey. Signatura GO-CO 1194.1 
Protocolo Final Data tópica y crónica: Lima 22 de julio de 1702

Destinatario: Señor Don Joseph de Antequera Henriquez [Al margen

$\underline{\text { Al dorso }}$

inferior izquierdo]

$\underline{\text { Al dorso }}$
$\underline{\text { Protocolo Inicial }}$
$\underline{\text { Cuerpo }}$

Data tópica y crónica: Lima 22 de julio de 1702

Destinatario: Al Señor Don Joseph de Antequera Henriquez

Protocolo Final Data tópica y crónica: Lima 15 de junio de 1749

Invocación: Crismón

\section{Lámina II $^{42}$}

En la fragata La Rosales remiti a vuestra señoria vaxo de partida de/rexistro tres caxones de pliegos con destino a la via reser/vada el consexo y a Cadiz y otro separado a vuestra señoria/ y proporcionandose la ocasión de seguir el mismo/ viage a Perico la Theresa paso a manos de vuestra señoria el adjun/to rotulado al excelentisimo señor Marques de la Ensenada/ para que con igual cuydado lo encamine a Cartaxena/ en la primera y mas pronta oportunidad que se/ ofrezcan y de su recibo me avisara vuestra señoria.

Fórmula de despedida: cuya vida guarde/ Dios muchos años.
Destinatario: Señor Don Dionisio de Alcedo y Herrera [Al margen inferior izquierdo]

Al dorso $\quad$ Data tópica y crónica: Lima 15 de junio de 1749

Destinatario: Al Presidente de Panama

Resumen: Remitiendole un pliego para/ la corte encargándole lo/ encamine en la primera ocasión a Cartaxena.

Protocolo Inicial Invocación: Crismón

Cuerpo

\section{Lámina III $^{43}$}

Los Oficiales Reales de las Caxas de Truxillo me han/ representado con fecha de 25 del proximo pasado que/ en ellas ya no existen mas que 100 quintales de azogue/ indicandome se les remitan con la posible pronti/tud 500 quintales mas a fin de que por falta de este in/grediente no resulte [Ilegible: presumido] al recomendable/ gremio de mineros y a los intereses de su magestad en sus/ reales quintos [tachado: y] condescendiendo con su instancia [tachado: solicitud] orde/no a vuestras mercedes verifiquen sin dilazion alguna la direccion/ de los azogues que solicitan dichos ministros/ y asi lo tendran entendido para su puntual cumpli/miento

Fórmula de despedida: Dios guarde muchos años.

Protocolo Final Data tópica y crónica: Lima 5 de julio de 1780

42 Ibídem. GO-CO 1 194.10

${ }^{43}$ AGN. Superior... GO-CO 1195.561 
$\underline{\mathrm{Al} \text { dorso }}$

\section{$\underline{\text { Protocolo Inicial }}$}

\section{$\underline{\text { Cuerpo }}$}

Destinatario: A los Oficiales Reales de las Caxas de esta capital [Al margen inferior izquierdo]

Data tópica y crónica: Lima 05 de julio de 1780

Destinatario: A los Oficiales Reales de las Caxas de esta Capital

Resumen Previniendoles provean con la posible prontitud las Caxas Reales de Truxillo con la cantidad de 500 quintales de azogues.

\section{Lámina $\mathbf{I V}^{44}$}

Invocación: Crismón

Dirección en vocativo: Excelentisimo Señor

Puede ser que el respeto de la presencia de vuestra excelencia me $\mathrm{a} /$ corte las resones que me asisten para fiar del gran/celo de vuestra excelencia el decempeño de mis conocidas obligaciones./ Dos meses avia que con el deseo de registrar mis acciones/ el superior dictamen de vuestra excelencia me puse con el rendimiento/ que devo a sus pies para la pretension que como en la/ alcaldia de esta ciudad vuestra excelencia fue servido honrrarme/ con la aprobacion del dictamen y prometerme el favor/ de su grandeza en esta conformidad he corrido el empe/ño que vuestra excelencia save y siempre con el seguro de que a lo menos/ no abria intimacion en contrario de parte de vuestra excelencia/ como lo an acreditado los mismos capitulares que en di/ferentes tiempos y ocaciones han ofrecido la elección a que/ siempre se ha servido vuestra excelencia de responder con la indiferen/cia que es de su gran justificacion y la que an procurado/ de calificar todos todos los señores virreies antecesores/ de vuestra excelencia por se esta una de las mas notorias ocasiones/ que puedan calificar el celo de un principe que govi/ erna con tanta justificacion cuio conocimiento me ha estor/vado el repitir cansancios a vuestra excelencia para insinuaciones/ favor de mi pretencion y la he corrido valiendome de / los medios onrrados que caven en mis obligaciones $\sin /$ (fol. vuelta) a derechos de las partes. Ahora señor los opositores han/ publicado que vuestra excelencia incinuaria a lo votos que la eleccion/se aga en un opositor mio y aunque esta superior disposicion posicion/ huviere sido antes como lo es ahora de mi veneracion no / puedo dejar de poner a los ojos de vuestra excelencia mis obligaciones/ y los demas procederes el justo sometimiento que podre tener/ en los limites del debido respeto a que de qualquiera ma/nera quede excluida mi pretencion con justificaciones/ de vuestra excelencia quando para estar a los pies de vuestra excelencia nadie/ con mas rendimiento ni con mas afecto que mi padre/ y yo y toda nuestra casa como lo dara a conocer la expe/riencia he llegado a

${ }^{44}$ AGN. Superior Gobierno. Oficios al Virrey GO-CO 2199.4 
Protocolo Final Data tópica y crónica: Lima y diciembre 31 de 1678 años.

\section{$\underline{\text { Protocolo Inicial }}$}

\section{$\underline{\text { Cuerpo }}$}

Fórmula nominal de despedida: Excelentisimo Señor

Fórmula de sometimiento: Puesto a los pies de vustra excelencia su mas rendi/do y reconocido criado

Validación: Don Luis de Santa Cruz y Padilla [firma y rúbrica]

presumir que serán voses del opo/citor y sin embargo he resuelto ponerme otra vez a los pies/ de vuestra excelencia suplicandole que abiendo ya corrido mi empeño tan/ adelante fiado en el credito de no tener vuestra excelencia superiores mo/tivos de gobierno para lo contrario se sirva honrrarme/ y aserme merced como lo espero de la superior grandesa/ de vuestra excelencia en su dilatado gobierno como lo esperamos conoce/ra el decempeño de mis obligaciones

Fórmula de despedida: en el mas afectuoso/ rendimiento de mi padre y de mi y de mis hermanos/ y toda mi familia a los pies de vuestra excelencia cuia vida guarde/ Dios como he menester y desea este reyno

\section{Lámina $\mathbf{V}^{45}$}

Invocación: Crismón

Dirección en vocativo: Excelentisimo Señor

Aviendo reconocido tan poco valida y acatado/ la fuerza de la verdad sobre las calumnias que tan/ injustamente se han imputado contra el capitan Pedro/ de Hendara theniente general de la provincia de/ Larecaxa y movidos del mal afeto que el tiene / an sucitado informe tan siniestro dando cuenta a / vuestra excelencia falasmente faltando en todo a la verdad/ por cuia causa no puedo escusar esta carta de informe/ para que conste a la justificada benignidad de / vuestra excelencia que por ocacion de tener mi beneficio/ que es el pueblo de Guaycho mui cerca de asiento/ de Sunchulli me halle presente el dia de la Glo/riosa santa Rosa en que por commocion del justi/cia maior del lugar se formo motin contra el/ corregidor de dicho partido y asi memsmo fui con/teste del extrepito judicialy aceleración con que /precedió el dicho justicia mayor aprender al corre/gidor acompañado de mucho numero de gente de/ (folio vuelta) su parcialidad y viendo la demás gente semejante/desorden y la displicencia con que tratavan a / un corregidor y ministro de su magestad se hubo de/ alterar contra los parciales del dicho justi/cia maior año averse interpuesto el thenien/te general Pedro de Hendara a pasificar dicho/ motin como lo ha acostumbrado en todas las/ ocasiones que sen ofrecido en dicho asiento para como/ tambien en la presente es notorio y manifiesto que /estando actualmente conversando en la puerta de/ la iglesia el dicho

${ }^{45}$ AGN. Superior... GO-CO 2199.12 
theniente general conmigo/ vino el alguasil maior a darle parte como ya avian sucedido muchas muertes y que fuese a obrar el tumulto originado del justi/cia maior Juan de Rada y su hermano/ a cuias instancias acudio con toda legalidad/ desapacionado de ambas partes atendiendo / solo a la quietud universal segun parecera en las pruebas jurídicas sirviendose vuestra excelencia de / mandar se siga por juicio de algun juez que atienda/ al conocimiento de esta verdad fio del gran celo de vuestra excelencia la tranquilidad de este negocio y / entretanto

Fórmula de despedida: suplico a nuestro señor que la excelentísima persona de vuestra excelencia muchos años.

Protocolo Final Data tópica y crónica: Guaycho y Marzo 29 de 1701.

Fórmula nominal de despedida: Excelentisimo Señor

Fórmula de sometimiento: Esta a los pies de vuestra excelencia con todo rendimiento

Validación: Sebastian Ramirez [firma]

$\underline{\mathrm{Al} \text { dorso }}$

Invocación: Crismón

Data tópica y crónica: Guaycho 29 de Marzo de 1701

Destinatario: Lizenciado Sevastian Ramirez Cura

Resumen: Da noticia de lo que paso en el tumulto y abona al theniente general Pedro de Endara 


\section{Lámina I}

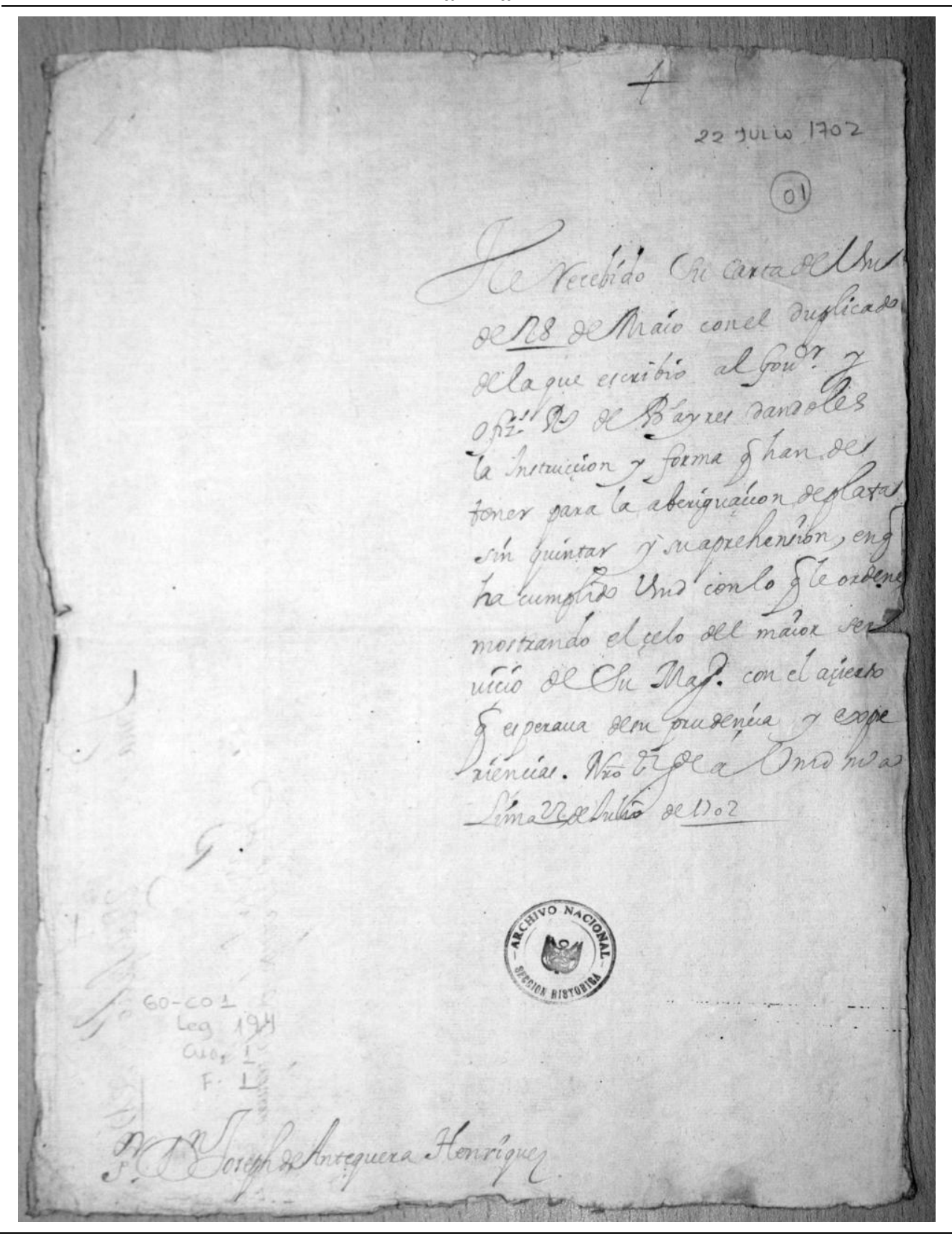




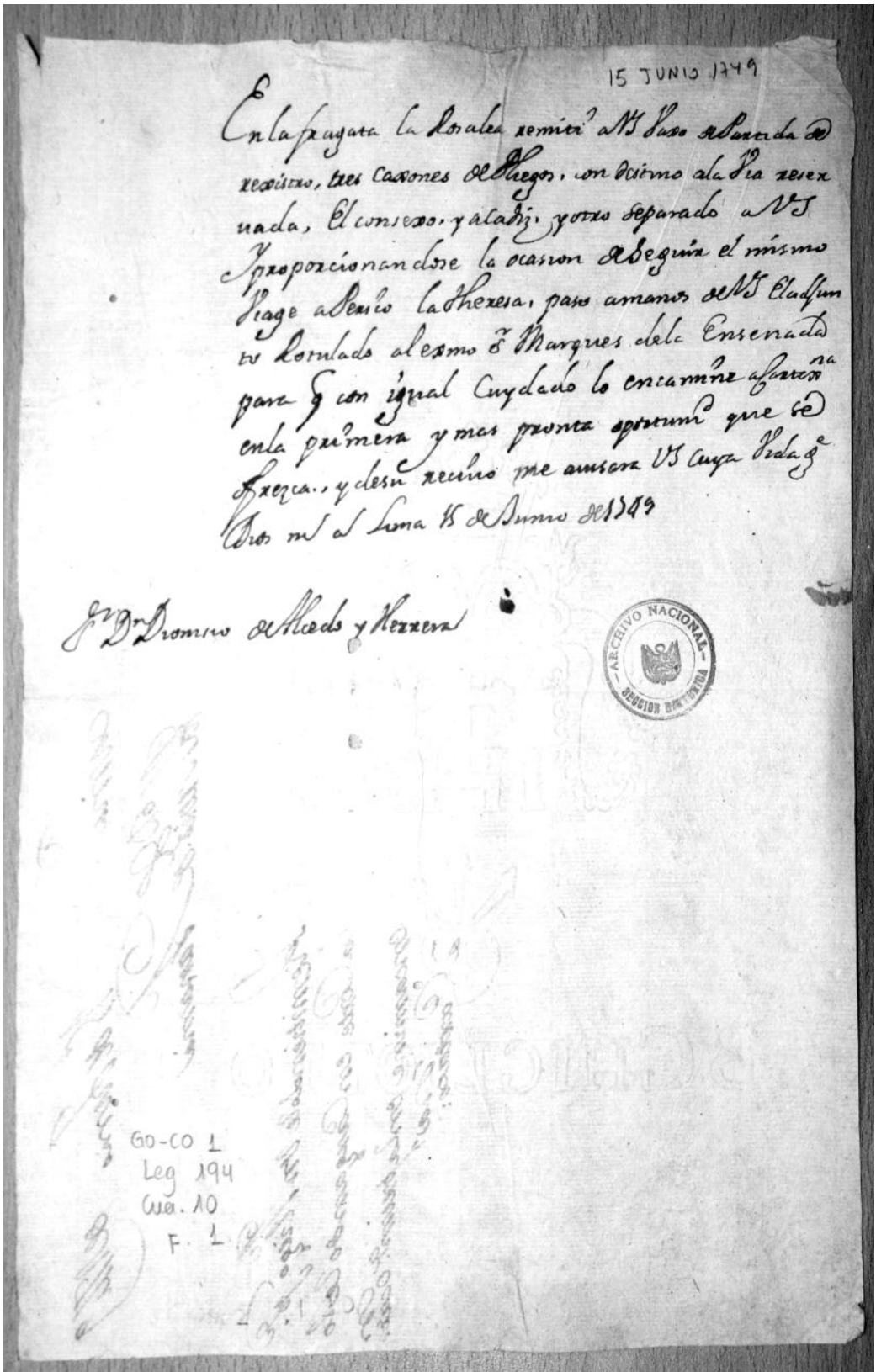




\section{Lámina III}

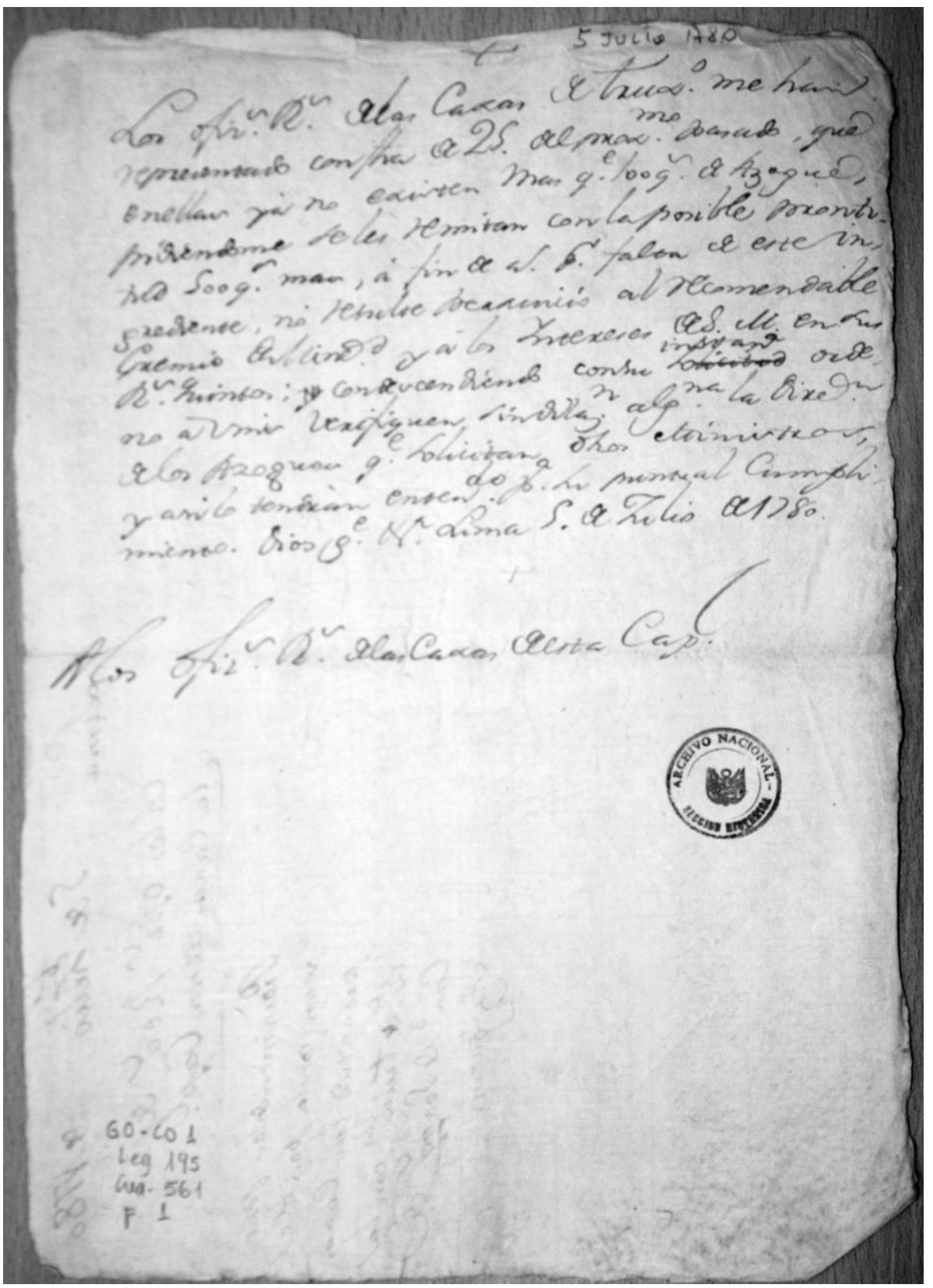




\section{Lámina IV}

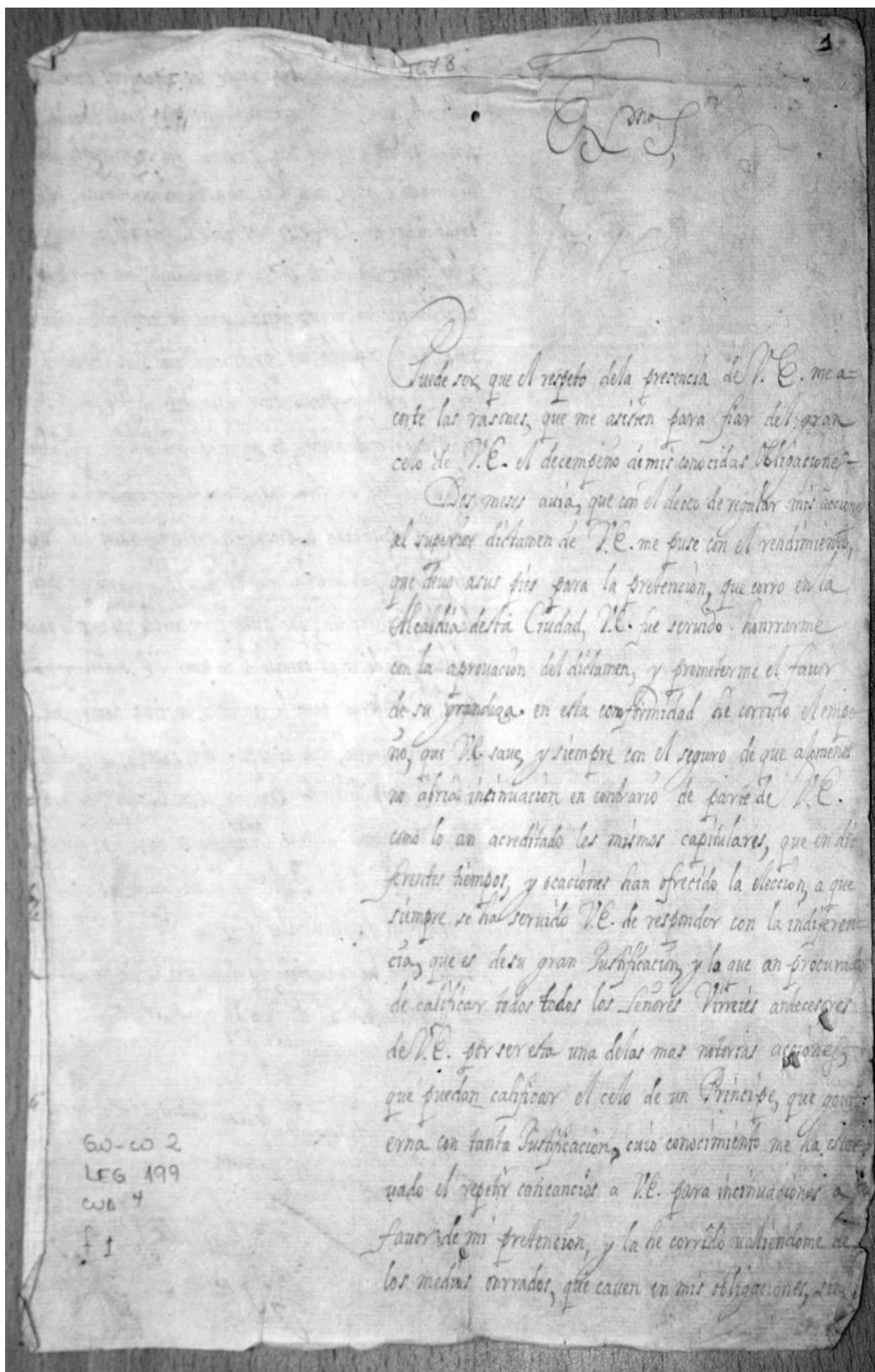




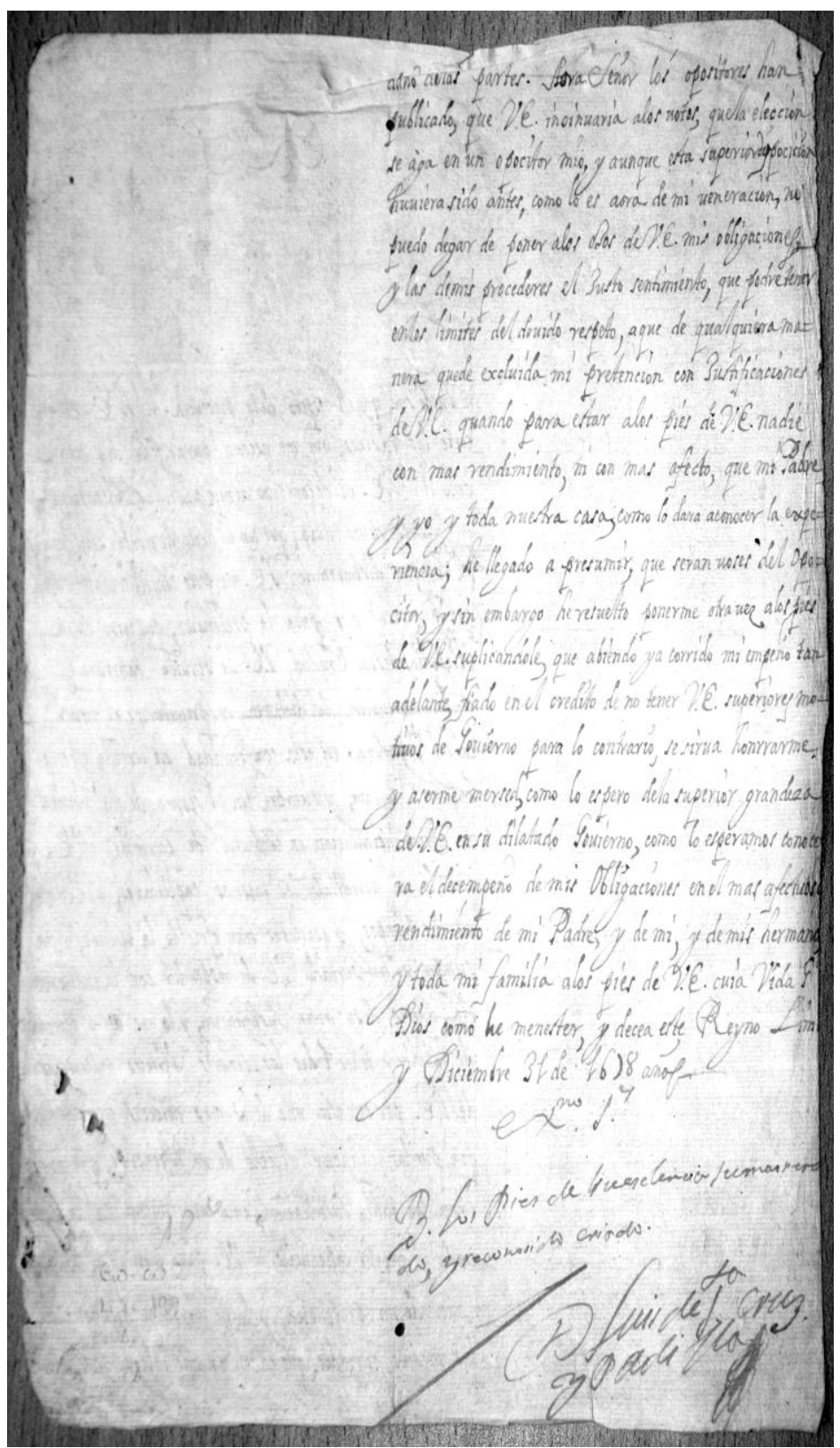




\section{Lámina V}

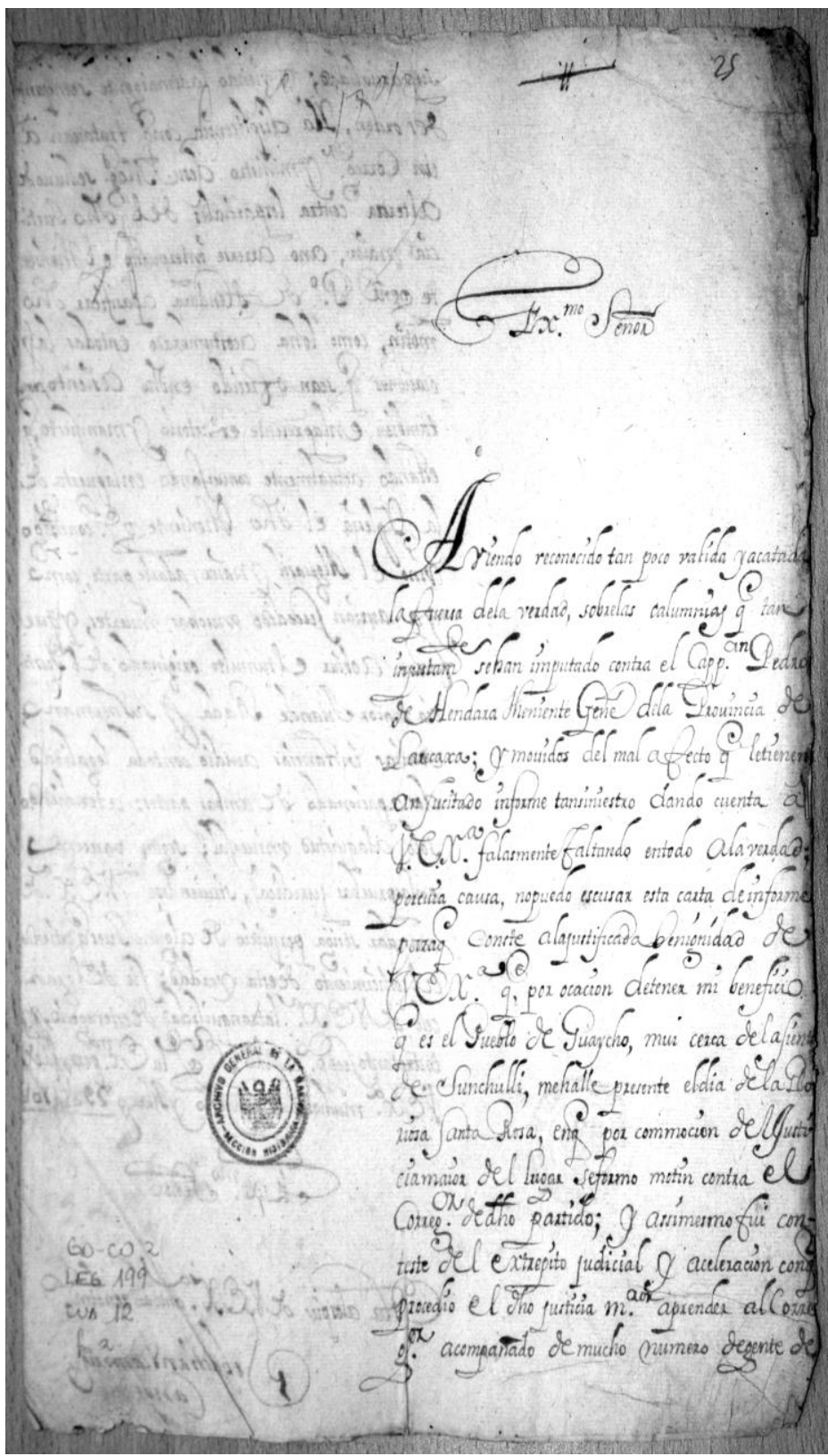




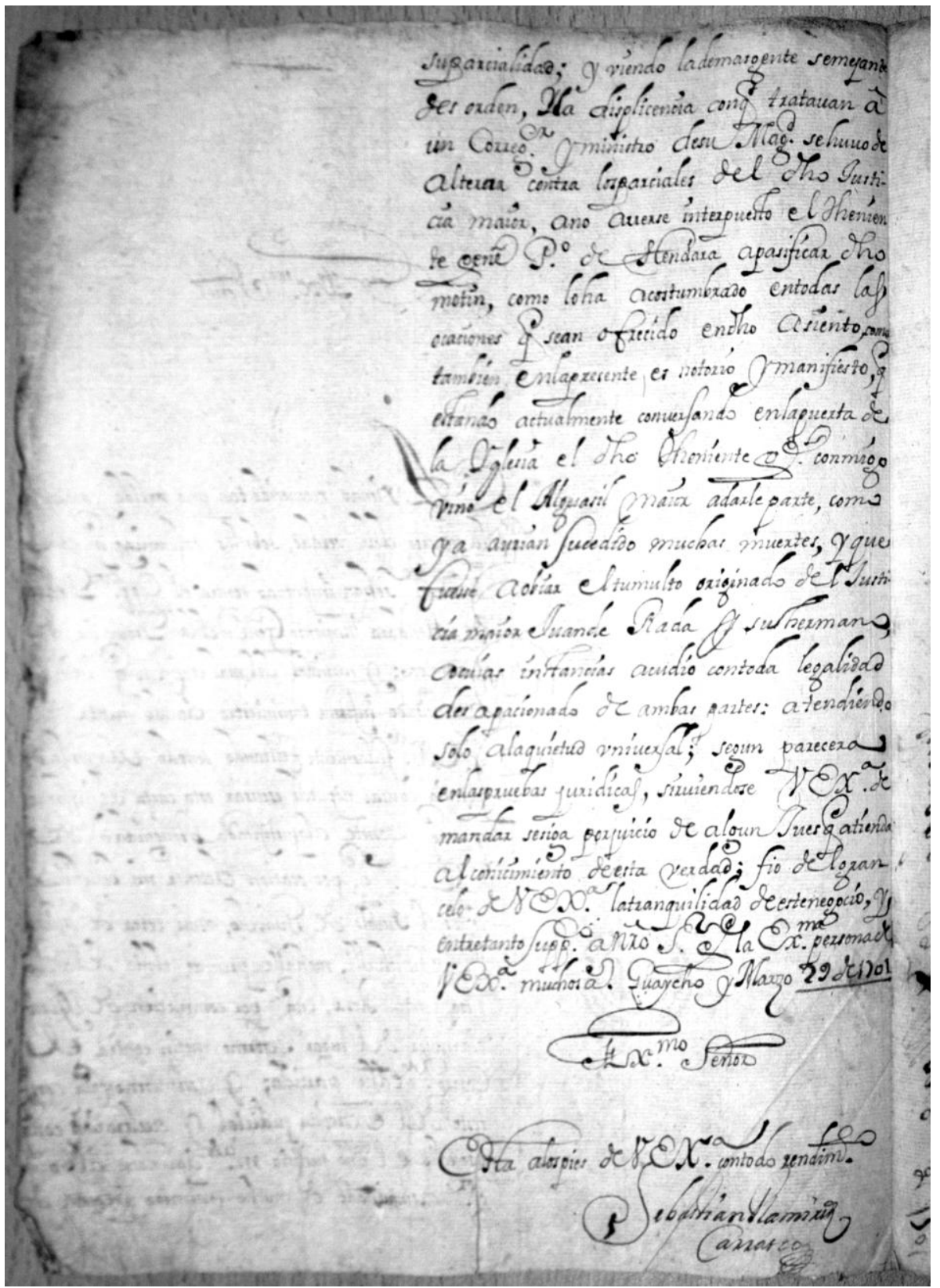




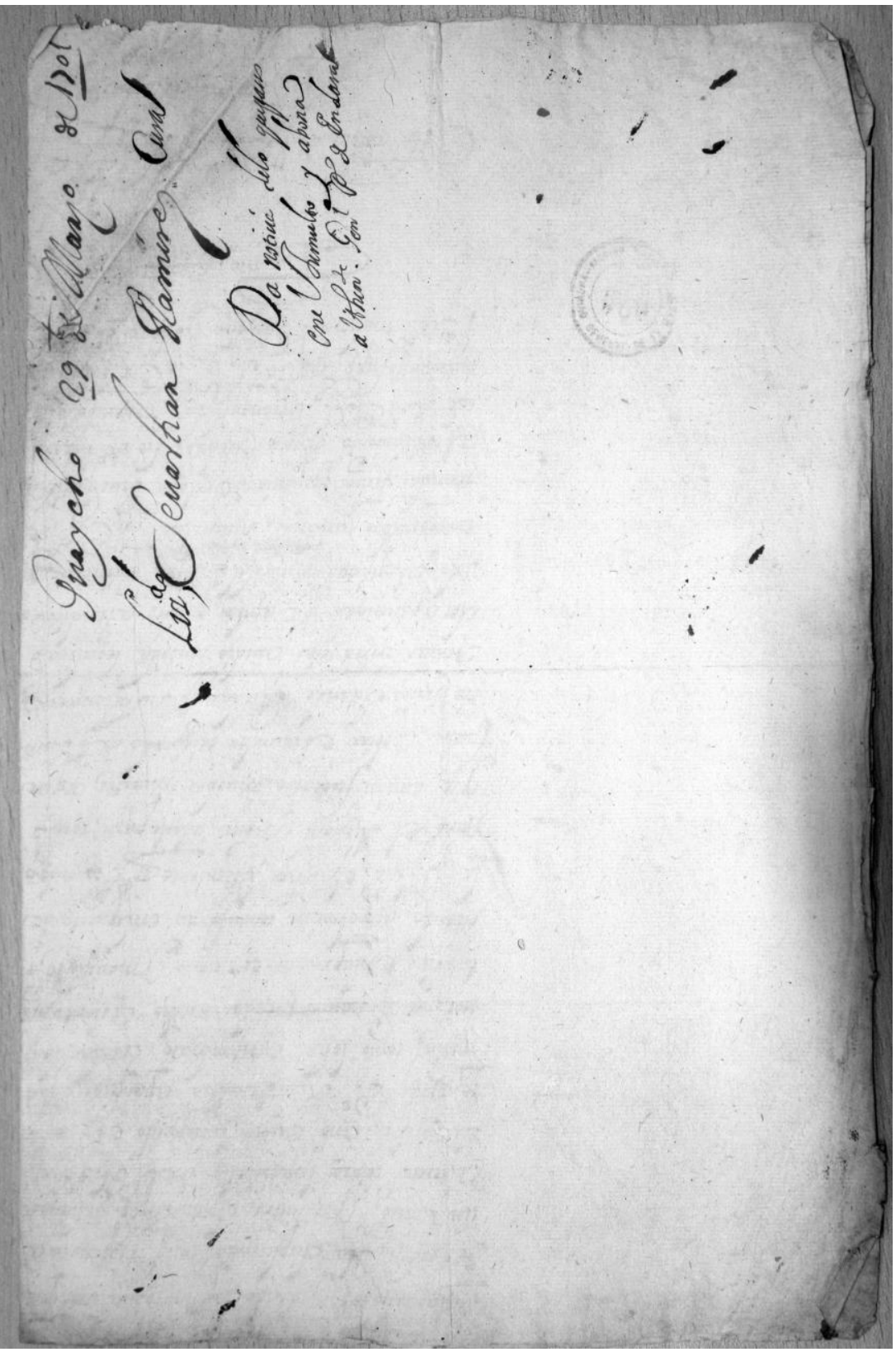




\section{REFERENCIAS BIBLIOGRÁFICAS.}

Bedmar SANCRistobal, M. E. (2003). «La importancia de nuevos materiales documentales para la resolución de viejos problemas» [recurso electrónico]. Res Diachronicae, 2003, $\mathrm{n}^{\circ}$ 2. <http://www.ajihle.org/resdi/docs/Numero2/.../ Bedmar_ Sancristobal.pdf [Consultado: 25.08.2010].

Bono, J. (1996). «Diplomática Notarial e Historia del Derecho Notarial». [recurso electrónico]. Cuadernos de Historia del Derecho, 1996, n³. <http://www. revistas. ucm.es/der/11337613/articulos/CUHD9696110177A.PDF .> [Consultado: 23.01.2011].

ENCINAS, D. DE. (1945). Cedulario Indiano. Madrid: Cultura Hispánica. Libros I, II y III.

GALENDE DíAZ, J. C. (2001). «El proceso inquisitorial a través de su documentación. Estudio diplomático» [recurso electrónico]. Espacio, Tiempo y Forma, IV, H. Moderna, 14, 2001. 〈http:// e-spacio.uned.es/fez/eserv.php?pid=bibliuned:ETFSerie4...3356...> [Consultado: 15.04.2011].

Galende DíAZ, J.C., SAlAmanCA LóPEZ, M. (2005). «Las misivas reales durante la segunda mitad del siglo XVI» [recurso electrónico]. IV Jornadas Científicas sobre Documentación de Castilla e Indias en el siglo XVI. Universidad Complutense de Madrid, 2005. <http://www.ucm.es/centros/cont/descargas/documento11360.pdf>. [Consultado: 30.05.2011].

GIL ARRAN, M.C. (1986). «Contribución al Estudio Lingüístico del Siglo XVII». [recurso electrónico]. Cauce Revista de Filología y su Didáctica, 1986, 9 http://www. cvc.cervantes.es/literatura/cauce/pdf/cauce09/cauce_09_004.pdf [Consultado: 31.05. 2011].

GuEvarA GIL. A. (1996). «Una hipótesis de trabajo sobre la función de la carta de venta en el derecho colonial peruano ¿formalidad esencial o legalismo obsesivo?» [recurso electrónico]. Revista de Estudios Históricos-Jurídicos, 1996, vol. XVIII. <http:// www.restudioshistoricos.equipu.cl/index.php/rehj/article/viewFile/.../232.> [Consultado: 04.02.2011].

HAMPE MARTíneZ, T. (1990-1992). «Esbozo de una transferencia política: asistentes de Sevilla en el gobierno virreinal de México y Perú». Revista Histórica, XXXVII.

Heredia Herrera, A. (1985). Recopilación de Estudios de Diplomática Indiana. Sevilla: Excma. Diputación Provincial de Sevilla.

Hidalgo NucherA, P. (1994). «El Escribano Público entre Partes o Notarial en la Recopilación de Leyes de Indias de 1680» [recurso electrónico]. Espacio, Tiempo y Forma, 1994, serie IV, t. 7. <http://www.e-spacio.uned.es/fez/eserv.php?pid= bibliuned:ETFSerie4...3C09... >. [Consultado: 18.07.2011]

HuAmANCHUMO DE LA CuBA, O. (en preparación) «Tradiciones Discursivas en Documentos Petitorios Indianos (Perú Siglo XVI)» Actas del VIII Congreso Internacional de Historia de la Lengua Española, Santiago de Compostela, 14-18 de Septiembre de 2009, 1-15 (manuscrito).

Jesús Benítez, M. (2004). «Las cartas de Pedro Sarmiento de Gamboa: la escritura de la suplica» [recurso electrónico]. Telar. Revista del Instituto Interdisciplinario de Estudios Latinoamericanos (IIELA), 2004, 1. <http://www.filo.unt.edu.ar/centinti/iiela/ revista_telar/revistas/1/2.pdf> [Consultado: 05.03.2011]. 
Lohmann Villena, G. (2005). «El Secretario Mayor de Gobernación del Virreinato del Perú: notas para su estudio histórico institucional» [recurso electrónico]. Revista de Indias, 2005, vol. 65. $\mathrm{n}^{\mathrm{o}} 234<\mathrm{http}: / / \mathrm{www}$. revistadeindias.revistas.csic.es/index.php/.../ article/.../393.> [Consultado: 20.04.2011].

LORENZO CADARSO, P. L (2002). «La correspondencia administrativa en el Estado Absoluto Castellano (siglo XVI-XVII)» [recurso electrónico]. Tiempos modernos: Revista Electrónica de Historia Moderna, 2002, vol. 3, $\mathrm{n}^{\mathrm{o}}$ 5, <http://www.tiemposmodernos.org/include/getdoc.php?id=124article...> [Consultado: 10.11.2010].

LóPeZ VillalBA, J. M. (1997). «Las relaciones del concejo bajo medieval. Estudio diplomático de las cartas concejiles de Guadalajara (1391-1496)». [recurso electrónico]. Espacio, Tiempo y Forma, 1997, serie III, $\mathrm{n}^{\mathrm{o}} 10$, <http://www.espacio.uned.es/fez/eserv.php?pid=bibliuned:ETF0A818B05-68AE.... [Consultado: 12.03.2011].

LuZ Urquijo, J. M. (1998). El Agente de la Administración Pública en Indias. Buenos Aires: Instituto de Investigaciones de Historia del Derecho.

Morales Folguera, J. M. (2001). La Construcción de la Utopía. El Proyecto de Felipe II (1556-1598) para Hispanoamérica. Madrid: Biblioteca Nueva.

Moreno Burgos, H. (2009). «Fórmulas de cortesía en las cartas de Pedro de Valdivia» [recurso electrónico]. Protocolo. Org. Beta 2.1. <http://www. protocolo. org/.../fórmulas_de_cortesía_en_las_cartas_> [Consultado: 18.02.2011].

MOREYRA Y PAZ SOLDÁN, M. (1952). «Introducción a documentos y cartas de la Audiencia y del virrey Marques de Montesclaros». Revista Historia, XIX.

PRADELLS NADAL, J. y BALDAQUI ESCANDELL, R. (1986-1987). «Los archiveros de la primera secretaria de estado (siglo XVIII)» [recurso electrónico], 1986-1987, nº 6-7. <http://www.rua.ua.es/dspace/bitstream/10045/5008/1/RHM_06-07_06.pdf>. [Consultado:04.03.2011]

Real DíaZ, J.J. (1970). Estudio Diplomático del Documento Indiano. Sevilla: Escuela de Estudios Hispanoamericanos.

ReAles CÉdulas, ReAles ORdenes, DeCretos, Autos y Bandos Que SE GUARDAN EN EL ARCHIVo HistóRICO. Ministerio DE HACIENDA Y COMERCIO. (1947). Lima: Archivo Histórico Sección Colonial.

RECOPILACIÓN DE LEYES DE INDIAS [recurso electrónico]. Archivo Digital del Congreso de la República del Perú. 〈http:www.congreso.gob.pe/ntley/LeyIndiaP.htm.>. [Consultado: 03.04.2011].

Salinas y CóRDOVA, B. DE. (1957). Memorial de las Historias del Nuevo Mundo del Pirú. Lima: Universidad Nacional Mayor de San Marcos.

VALENCIA ÁlVAREZ, G. (2002). «Superior Gobierno: su reorganización y descripción dentro del proyecto de Informatización del Archivo General de la Nación». Revista de Archivo General de la Nación (AGN), 24, 